\title{
Escritas de Si e a emancipação feminina
}

\author{
Kassiana Braga
}

Resenha recebida em 07/12/2015 e aprovada em 27/12/2015.

Margareth Rago, professora da Universidade Estadual de Campinas (Unicamp), historiadora e militante feminista desenvolve pesquisas com temáticas relacionadas ao gênero, feminismos, memoria, anarquismo, processos de subjetivação entre outros diversos assuntos. Atualmente coordena com a professora Dra Tânia Navarro Swain e Dra. Marie-France Dépèche a revista digital feminista internacional Labrys sendo também coeditora da revista Aulas - (Unicamp).

Escreveu inúmeros livros como Do cabaré ao lar publicado no ano de 1985, A utopia da cidade disciplinar. Brasil 1890-1930 (1985), Os Prazeres da Noite. Prostituição e códigos da sexualidade feminina em São Paulo, 1890-1930 (1991), Narrar o Passado, Repensar a História, com Aloísio Gimenez (2000), Entre a História e a Liberdade: Luce Fabbri e o anarquismo contemporâneo (2001) e Foucault: para uma vida não fascista publicado em 2009.

Em $A$ aventura de contar-se feminismos, escrita de si e invenções da subjetividade lançado em 2013, Rago apoiada nos trabalhos de Michel Foucault entre outros teóricos, empreende uma profunda reflexão sobre o movimento feminista (1960-1970) que lançou novas praticas sociais, culturais e politicas na sociedade brasileira fazendo com que muitas mulheres se libertassem dos antigos papéis sociais ditados pela moral vigente. Nesse sentido, a historiadora analisa as narrativas autobiográficas de Criméia Alice de Almeida Schmidt, Gabriela Silva Leite, Ivone Gebara, Maria Amélia de Almeida Teles, (Amelinha), Maria Lygia Quartim de Moraes, Norma de Abreu Telles e Tania Navarro Swain, mulheres que construíram a partir de uma reflexão sobre si novos espaços subjetivos e de gênero modificando desse modo, a maneira de serem e estarem no mundo.

O livro foi organizado em três partes intituladas: Experimentação, Cartografias e Um lugar no Mapa. Nessa obra, Rago dedica-se a narrar um panorama sobre as trajetórias de vida de sete mulheres que apesar de possuírem historias pessoais distintas se assemelham por terem vivenciado o período da ditadura civil militar (1964-1985) brasileira. Além disso, são militantes que de um modo ou de outro se reconstruíram a partir de novas referencias de conduta não se restringindo ao destino reservado as mulheres até então: o de serem apenas mães e donas de casa limitadas ao ambiente doméstico. Dessa maneira, ocupam os espaços públicos e as universidades vinculando-se a outros movimentos, partidos e organizações.

Interessada em compreender os novos modos de existência dessas mulheres que a historiadora mergulha em inúmeras fontes como os relatos autobiográficos, em processos penais e entrevistas gravadas por ela mesma ou publicadas anteriormente. Nesse sentido, Rago relata as experiências intensas de Amelinha e Criméia, filhas de militante do Partido Comunista (PCB) que também entraram para a militância partidária e posteriormente fizeram parte da Guerrilha do Araguaia (1966-1975) defendendo a luta armada no campo, objetivando 


\title{
ESCRITAS DE SI E A EMANCIPAÇÃO FEMININA
}

\section{KASSIANA BRAGA}

construir o socialismo no Brasil. Relata ainda, as suas dificuldades, a prisão em São Paulo na década de 1970 bem como a violência psicológica e física sofrida por ambas como os espancamentos, tortura, ameaça de sequestros e a perda de entes queridos no período da militância. Neste sentido, contribui para que a historia de luta das irmãs Criméia e Amelinha seja divulgada:

\begin{abstract}
Essas considerações ajudam a refletir sobre a experiência dolorosa dessas suas militantes e a entender um pouco mais a força de sua coragem também no ato de recordar o passado. Nesse caso, rememorar é dar testemunho sobre acontecimentos políticos trágicos da vida brasileira, o que implica uma reatualização da dor sentida no passado, num momento de grande solidão e fragmentação - em que Amelinha se encontra separada do marido e dos filhos pequenos, enquanto Criméia se vê ameaçada de interrupção da gestação do seu filho. Mas é também um modo de criar novos horizontes, já que, nessas narrativas, articulam-se historias de grande capacidade de superação da dor ${ }^{\text {II }}$.
\end{abstract}

Além desse ponto, também se debruça a narrar à trajetória de Ivone Gebara, que aos 22 anos de idade tornou-se freira, conquistando a sua tão sonhada liberdade. Apesar de fazer parte da Congregação das Irmãs de Nossa Senhora Cônegas de Santo Agostinho também foi professora em São Paulo, conhecendo muitos militantes de esquerda, descobrindo leituras marxistas ao ponto de tornar-se socialista. Concluiu o doutoramento em Filosofia pela PUC São Paulo, lecionando posteriormente no Instituto de Teologia do Recife, dando assessorias aos movimentos populares, oferecendo cursos ao movimento MST, ao movimento de trabalhadoras rurais e para os grupos de mulheres da periferia, entre outros.

Contempla ainda, os relatos de vida de Norma Telles, autora de Belas e feras publicado em 2007 e historiadora que diferentemente das mulheres citadas anteriormente, não fora uma militante de esquerda, mas uma mulher igualmente libertária que viajou a vários países conhecendo inúmeras culturas, dedicando-se a estudar posteriormente os relatos de vida de aventureiras e viajantes.

Focada no feminismo e na militância de esquerda no Brasil narra os relatos de vida da professora Maria Lygia Quartim de Moraes, autora da autobiografia Vida de Mulher publicada no ano de 1981, também militante politica que viveu o exilio em Havana em 1969, posteriormente no Chile e na França presenciando diretamente as lutas sociais ocorridos na América Latina.

Ao relatar a trajetória pessoal e profissional da historiadora feminista Tania Swain que morou na França durante muitos anos, adquirindo grande experiência e influencia do pensamento feminista francês, Rago traça um panorama sobre os movimentos feministas que estavam emergindo em várias partes do mundo a partir do final da década de 1960. Desse modo, cita as primeiras revistas feministas que foram publicadas nesse contexto como Naturellement, Le Corps Approprié, Anotomie Politique e Libération des Femmes bem como as principais referencias teóricas do momento como Simone de Beauvoir, Christine Delphy, Nicole Claude Mathieu, Monique Wittig, Geneviève Fraise e Luce Irigaray. Nesse sentido, a historiadora mostra as profundas transformações sociais e de gênero que estavam ocorrendo na vida das mulheres a partir do contato com o movimento feminista internacional.

A historia de vida de Gabriela Silva Leite, prostituta criada em uma família de classe média em São Paulo que publicou dois livros autobiográficos intitulados Eu mulher da vida (1992) e Filha, mãe, avó (2009), responsável por criar a ONG DAvida também foi analisado pela historiadora. Apesar de não ser partidária e nem militante, Rago mostra que Gabriela 


\section{ESCRITAS DE SI E A EMANCIPAÇÃO FEMININA}

\section{KASSIANA BRAGA}

também acabou presenciando a violência policial no contexto da ditadura, como nos mostra no excerto a seguir:

Se Gabriela escapa das perseguições policiais contra os militantes de esquerda, logo se daria conta do peso dos preconceitos enfrentados pelas prostitutas e teria de enfrentar outras frentes o exercício da violência policial, num pais sob o comando dos militares. Em 1979, já na prostituição, participa da organização do primeiro movimento das prostitutas, em uma manifestação na Praça da Sé em São Paulo, em reação à violenta repressão que se deflagra contra elas e os travestis, comandada por um delegado. Toque de recolher a partir de 22 horas, espancamentos, prisões e torturas geraram uma reação de revolta profunda nessa população, que ganha o apoio dos donos de bares, garçons, cafetinas, entre outros"III.

A partir da analise dos relatos de vida das mulheres elencadas, atenta aos discursos, as escolhas e as narrativas autobiográficas, Rago consegue identificar as mudanças que ocorreram em suas vidas, seja por meio da militância politica, por suas atividades acadêmicas, vinculadas ao movimento feminista ou mesmo dentro de outras organizações.

Também observa que o feminismo é concebido por elas de maneiras diferentes. Além disso, todas foram ativistas que combateram com bravura a ditadura civil militar no Brasil.

Como nos mostra a historiadora, essas mulheres romperam com normas de conduta com os padrões morais, sociais e culturais promovendo nesse sentido, novos modelos de subjetividade. Foram mulheres que se emanciparam intelectualmente, escrevendo, estudando, ocupando novos espaços profissionais impensáveis em décadas anteriores:

As mulheres cujas trajetórias apresentamos, assim como uma infinidade daquelas que atuam politicamente no movimento feminista brasileiro, em suas inúmeras frentes, continuam afirmando-se como feministas. Contra as pedras lançadas no presente ou desde o passado, ousam assumir os feminismos que ajudam a construir e a movimentar com suas atitudes, suas práticas, suas ações, suas experiências, seus pensamentos, seus desejos e seus afetos ${ }^{\mathrm{IV}}$.

Desse modo essas militantes, apesar de constituir apenas uma parcela, um grupo pequeno composto por mulheres brancas intelectualizadas, essas, foram responsáveis por inúmeras transformações sociais, principalmente no que se refere "as novas possibilidades de existência para as mulheres em geral, para além do casamento e da maternidade obrigatória como finalidades exclusivas" $\mathrm{V}$.

Essa reflexão proposta pela historiadora no presente trabalho vem a dialogar com certas demandas dos movimentos feministas na atualidade que estão a todo vapor em busca de melhorias na condição de vida, nos direitos e na autonomia das mulheres. Neste sentido, estão protagonizando mudanças, organizando eventos, projetos de leis, passeatas e manifestações em prol da emancipação feminina. Ou seja, se as militantes durante a década de 1970 foram à luta e ocuparam novos espaços e criaram para si novos modelos de subjetividade, nos dias de hoje o trabalho de desconstrução do pensamento falocentrico e masculinista continua a ser colocado em pratica, sendo mais uma ferramenta de resistência e, sobretudo de transformação.

Em suma, A aventura de contar - se Feminismos, escrita de si e invenções da subjetividade é um livro cheio de informações, contribuindo com a historiografia atual sobre a temática do feminismo, interessando também aos estudiosos das escritas de si ou mesmo os que pesquisam o período da ditadura civil militar e as questões de gênero, pois fornece profunda e sólida reflexão sobre tais assuntos.

Cadernos do Tempo Presente, n. 22, dez.2015/jan. 2016, p. 82-85|http://www.seer.ufs.br/index.php/tempo 
KASSIANA BRAGA

\section{Notas}

\footnotetext{
${ }^{\mathrm{I}}$ Kassiana Braga é graduada em História pela Faculdade de Ciências e Letras - UNESP - Campus de Assis e aluna do curso de pós-graduação (mestrado) pela mesma universidade, na qual desenvolve a pesquisa A senhora dona da memória: autobiografia e memorialismo em obras de Zélia Gattai, fomentada pelo Conselho Nacional de Desenvolvimento Científico e Tecnológico (CNPQ). E-mail: kassianahistoriabraga@gmail.com.

${ }^{\text {II }}$ RAGO, Margareth. A aventura de contar-se Feminismos e invenções da subjetividade. Campinas- SP: Editora da Unicamp, 2013, p. 73.

III Ibidem, p. 115.

IV Ibidem, p. 314.

${ }^{\mathrm{v}}$ Ibidem, p. 317.
}

\section{Referência bibliográfica.}

RAGO, Margareth. A aventura de contar-se - Feminismos e invenções da subjetividade. Campinas - SP. Editora da Unicamp, 2013, 341 p. 